\title{
Endoparasites in Chanos chanos (Forsskal, 1775) from the wetlands of Zamboanga City, Western Mindanao, Philippines
}

Roldan T Echem*, Herbert M Barba, Guangyao Li, Fang Peng and Nikka Joy C Buenaventura

Department of Biology, Western Mindanao State University, Zamboanga City, Philippines

\begin{abstract}
Chanos chanos (milkfish) locally known as Bangus is the main aquaculture product of the Philippines. The status of bangus production in Zamboanga City declined from 2012-2016. Diseases in C. chanos were known to be caused by parasites and have remained an issue to fish farming. Some of the parasites have been discovered to have zoonotic potential in mammalian hosts including man making them of public health importance. In this study, the identification, intensity, prevalence and biometric relations of endoparasites in C. chanos were determined. A total of 120 juvenile bangus were collected in the wetlands of Zamboanga City from July 2016 to August 2016. There were 4 endoparasites identified namely: Ichtyobodo sp., Trichodina sp., Acanthocephalans spp. and Diphyllobothrium latum. The most prevalent was Ichtyobodo sp. $(40 \%)$ and the least prevalent was $D$. latum $(1.66 \%)$. Ichtyobodo sp. has the highest mean intensity (4.39) found in the gills and $D$. latum has the lowest mean intensity (0.2) found in the intestine. Pearson's Correlation Coefficient Analysis revealed a negative correlation between fish length and number of endoparasites $(-0.17)$, fish weight and number of endoparasites $(-0.27)$ and body height and the number of endoparasites $(-0.31)$. However, there were high correlations between fish length and fish weight $(0.78)$, fish length and fish height (0.61) and fish weight and fish height (0.73).
\end{abstract}

Keywords: Host-parasite; Fish diseases; Diphyllobothrium; Protozoans; Pathogen.

\section{Introduction}

Disease is an important factor in fish production, and fish as one of the commercially important source of animal protein is susceptible to infections by various parasites. These diseases are closely linked to environmental deterioration and stress. The importance of parasitic infection on fish production has remained an issue to fish farming industry [1]. Diseases are caused by many parasites including protozoans and helminthes. Among the diseases caused by the protozoans are Amyloodioniosis or Velvet Disease, Ichthryophiriasis or White spot Disease, Trichidiniasis, Brooklynelliosis and Cryptobiosis or Trypanosomiasis. Parasitic Helminthes include Monogenea, Trematodes, Cestodes, Nematoda and Acanthocephalans [2]. Lio-Po [3], reported that intoxication of milkfish in freshwater systems has caused massive fish kills in the Philippines.

Cases of diseases occur among milkfish and outbreaks of these diseases attributed to parasites were summarized by Velasquez [4,5]. Subsequent reports included other pathogenic organisms [6,7]. Major diseases causing significant mortality among milkfish and other fish in the Philippines were described in a recent report [8]. For fish in a fishpond, infestation may result in death and economic loss.

Chanos chanos (milkfish) locally known as Bangus is the main aquaculture product of the Philippines. It is one of the most popular seafood dishes in the country [9]. Milkfish is considered to be one of the most important fish species farmed in the Philippines which is usually cultivated in freshwater, brackish water and marine environments. It continued to provide affordable source of protein for many of the people and also livelihood for most of the local families which work in Aquaculture [10]. According to Philippine Statistics Authority (PSA in 2015), there was a decline rate of production of milkfish in Zamboanga City from 2012-2015. There are several reasons that may account for the low production rate. Most of the milkfish which are being cultured in fish ponds and are plagued with diseases, acid soil and deteriorating water quality that might lead or result to low production [11].
Fish cultures provide a large reservoir of parasitic pathogen common to both wild and cultured fish [12]. Fish are hosts to a variety of parasitic organisms which can regulate fish population and community structure, reproduction and survival. They can decrease host fitness, and they can alter host behaviour and morphology which increases predation risks [13]. Parasites also compete for food thereby depriving fish of essential nutrients and inhibiting growth leading to death with consequent economic loss. Endoparasites are type of parasites that are found within the flesh, cavities of the host organism. These parasites can be usually found on the muscles, organs, membrane linings of the host organism [14]. There are many fish parasite that may infect human. Freshwater and brackishwater fishes are the source of human infections with foodborne trematodes. There were already estimated numbers of people who are currently infected with Fish-borne trematodes wherein it exceeds in 18 million and most of them are at risk [15].

The main purpose of this study was to determine the identification, intensity and prevalence of endoparasites in C. chanos in the gills, stomach and intestine. This study established the correlation between the fish length, fish fresh weight, height of the body to the number of endoparasites present in C. chanos. The data generated from this study could be used for public health awareness for the locals and provide information for bangus farmers for the better management of their fish ponds to reduce number of bangus infected with endoparasites.

\section{Materials and Methods}

A total of 120 samples of Chanos chanos were gathered from the fish

*Corresponding author: Echem RT, Department of Biology, Western Mindanao State University, Zamboanga City 7000, Philippines, Tel: (032) 991 1771; E-mail: roldanechem@gmail.com

Received February 03, 2018; Accepted May 25, 2018; Published May 31, 2018

Citation: Echem RT, Barba HM, Guangyao Li, Peng F, Buenaventura NJC (2018) Endoparasites in Chanos chanos (Forsskal, 1775) from the wetlands of Zamboanga City, Western Mindanao, Philippines. J Aquac Res Development 9: 535. doi: 10.4172/2155-9546.1000536

Copyright: @ 2018 Echem RT, et al. This is an open-access article distributed under the terms of the Creative Commons Attribution License, which permits unrestricted use, distribution, and reproduction in any medium, provided the original author and source are credited. 
Citation: Echem RT, Barba HM, Guangyao Li, Peng F, Buenaventura NJC (2018) Endoparasites in Chanos chanos (Forsskal, 1775) from the wetlands of Zamboanga City, Western Mindanao, Philippines. J Aquac Res Development 9: 535. doi: 10.4172/2155-9546.1000536

Page 2 of 5

ponds in Zamboanga City from July 2016 to August 2016. The total area of the fishponds was approximately 14 hectares. The juvenile bangus were 17 weeks and 5 days, 18 weeks and 5 days, 19 weeks and 5 days, 20 weeks and 5 days and 21 weeks and 5 days old. The bangus that were collected were placed in a plastic bag with labels and placed in a container filled with ice. Samples were brought to the Biology Laboratory, College of Science and Mathematics, Western Mindanao State University, Zamboanga City.

The total length of the body of bangus was measured using tape measure and the body height was measured using caliper. The fresh weight of the fish was measured using top loading balance (Shimadzu). To study the internal organs, the fish were dissected by opening the body cavity from posterior to anterior using dissecting tools and endoparasites were examined using hand lens. The prepared slide was examined under high power objective and low power objective using photomicrograph (ecoline). The gills $C$. chanos were scraped using scalpel and the scraping was mixed with 10 drops of $0.8 \%$ saline water in a petri dish. A drop of mixture was placed in a slide for microscopic examination. The stomach and intestine were removed from the fish. Each part was separated from each other and was dissected for individual inspection. Each part was washed with tap water after collecting endoparasites. The inner lining was scraped with scalpel to examine for microscopic parasites. The scraping was mixed with 10 drops of $0.8 \%$ saline water in a petri dish. a drop of a mixture was placed in a slide for microscopic examination. Slide was examined under high power objective and low power objective using photomicrograph (ecoline).

Samples were preserved in alcohol formalin acetic acid (AFA). AFA was prepared by adding $5 \mathrm{ml}$ glacial acetic acid and $5 \mathrm{ml}$ formalin to 90 $\mathrm{ml}$ of $70 \%$ ethyl alcohol. Samples on slides were stained with 1 drop of eosin solution. eosin solution was prepared by adding 1 gram of eosin y, $5 \mathrm{ml}$ of glacial acetic acid to 1 liter of $70 \%$ ethyl alcohol. Images of endoparasites were documented using a digital camera (Sony) for identification. All endoparasites were identified using identification guide by [2] and were confirmed by a parasitologist, Dr. Evelyn B. Campos, Ed.D. of Zamboanga State College of Marine Sciences and Technology (ZSCMST).

\section{Microscopic Examination of Major Parasitic Groups}

The Acanthocephala form a group of worms. They are cylindrical and are provided with spines in the proboscis immediately attaches itself by its proboscis to the intestinal mucosa of the milkfish. Ichthyobodosis is an important parasitic disease that has caused severe loss among milkfish. The disease is caused by heavy infections on skin and gills by parasitic flagellates belonging to the genus Ichthyobodo. Trichodina is a genus of ciliate alveolates that is ectocommensal or parasitic on milkfish. This parasite is usually found on the gills, skin or fins of the fish.

\section{Analysis of Data}

Endoparasites found at the gills, stomach and intestine of the fish during macroscopic and microscopic examination were identified, counted and photographed. The relations of the number of parasites and the fish length, fresh weight and body height were determined using Pearson Correlation Analysis [1]. The prevalence and mean intensity of the different endoparasites in the fish samples were accomplished by using the formula:
Prevalence $=\frac{\text { total number of Bangus infected with a particular parasite } \times 100}{\text { Number of bangus examined }}$

Mean Intensity $=\frac{\text { total number of particular parasites in a sample of bangus }}{\text { Number of infected bangus }}$

\section{Result}

Figures 1a,1b shows the morphological appearance of Icthyobodo sp. present in the gills of Chanos chanos observed under high power objective (400X). It is a parasite that is 5 to $20 \mathrm{~cm}$ in length, kidney shaped in appearance with 2 flagella attached to the ventral part of the body. Line drawing was derived from Read [16].

Figures 2a,2b shows the protozoan Trichodina sp. present in the gills of C. chanos observed under high power objective (400X). This protozoan parasite has saucer-like shape with a prominent tooth-like internal cytoskeleton ring. Photo of the same species observed under high power objective (400X) was obtained from Smith and Schwartz [17].

Figures 3a,3b shows the anterior portion of Acanthocephalan spp. The retractable proboscis with rows of hooks found at the intestine of $C$. chanos examined under high power objective (400X). The whole mount (a) and scanning electron micrograph of the heavily armed proboscis with recurved hooks (b) of Acanthocephalan spp. Figures 4a,4b shows the morphological appearance of Diphyllobothrium latum present in the intestine of C. chanos observed under high power objective (400X) with the operculum at the anterior portion of the egg (with arrow).

Figure 5 show that Ichtyobodo sp. has the highest number of individuals ranges from 15 to 33. Acanthocephalans spp. has 5, Diphyllobothrium latum and Trichodina sp. has the lowest number of individual (1) respectively. Ichtyobodo sp. has the highest mean intensity of 4.39 found in the gills of Chanos chanos. Trichodina sp. has a mean intensity of 0.4 found also in the gills. Acanthocephalans spp. and Diphyllobothrium latum has the lowest mean intensity of 0.25 and 0.2 respectively found in the intestine (Table 1).

The most prevalent endoparasite was Ichtyobodo sp. (40\%), followed by Acanthocephalans spp. (6.66\%), Trichodina sp. (3.33\%) and the lowest was Diphyllobothrium latum (1.66\%) respectively (Table 2). Pearson's correlation coefficient analysis revealed that there was negative correlation between fish length $(-0.17)$, fish weight $(-0.27)$ and body height $(-0.31)$ and the number of endoparasites present in Chanos chanos (Table 3).

Table 4 shows that Pearson's correlation coefficient analysis revealed that there were high correlations between fish length and fish weight

\begin{tabular}{|c|c|c|}
\hline Parts & Endoparasites & Mean intensity \\
\hline \multirow{2}{*}{ Gills } & Ichtyobodo sp. & 4.39 \\
\cline { 2 - 3 } & Trichodina sp. & 0.4 \\
\hline \multirow{2}{*}{ Intestine } & Acanthocephalans spp. & 0.25 \\
\cline { 2 - 3 } & Diphyllobothrium latum & 0.2 \\
\hline Stomach & -- & -- \\
\hline
\end{tabular}

Table 1: Mean intensity of endoparasites in C. chanos.

\begin{tabular}{|c|c|}
\hline Endoparasites & Prevalence (\%) \\
\hline Icthyobodo sp. & 40 \\
\hline Trichodina sp. & 3.33 \\
\hline Acanthocephalans spp. & 6.66 \\
\hline Diphyllobothrium latum & 1.66 \\
\hline
\end{tabular}

Table 2: Prevalence of endoparasites obtained in C. chanos. 
Citation: Echem RT, Barba HM, Guangyao Li, Peng F, Buenaventura NJC (2018) Endoparasites in Chanos chanos (Forsskal, 1775) from the wetlands of Zamboanga City, Western Mindanao, Philippines. J Aquac Res Development 9: 535. doi: 10.4172/2155-9546.1000536

Page 3 of 5

\begin{tabular}{|c|c|c|c|c|}
\hline Category & df & Computed value(r) & Tabular value(t) \\
\hline Fish length & 28 & $-0.17^{*}$ & 0.361 \\
\hline Fish weight & 28 & $-0.27^{*}$ & 0.361 \\
\hline Body height & 28 & $-0.31^{\star}$ & 0.361 \\
\hline
\end{tabular}

Not significant $=^{*}$ significant ${ }^{* *}$

Table 3: Pearson's correlation between number of endoparasites and fish length, weight and height of $C$. chanos.

\begin{tabular}{|c|c|c|c|}
\hline Category & df & Computed value $(\mathbf{r})$ & Tabular value (t) \\
\hline Fish length vs. Fish weight & 28 & $0.78^{\star *}$ & 0.361 \\
\hline Fish length vs. Fish height & 28 & $0.61^{* *}$ & 0.361 \\
\hline Fish weight $v$ s. Fish height & 28 & $0.73^{\star *}$ & 0.361 \\
\hline
\end{tabular}

Table 4: Pearson's correlation between fish length, fish weight and fish height $C$. chanos.
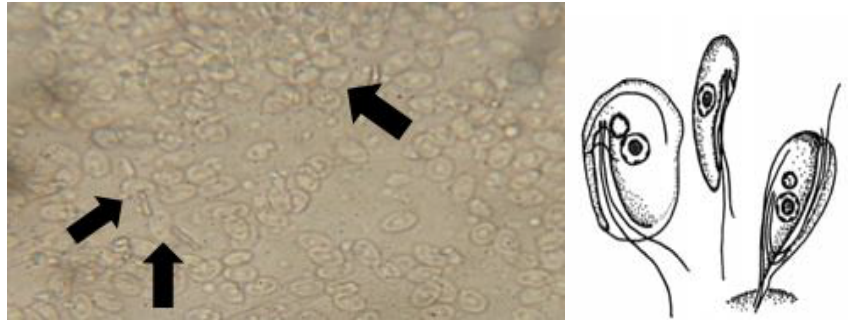

Figure 1a: Ichtyobodo sp. found at the lining of the gills, HPO (400X).

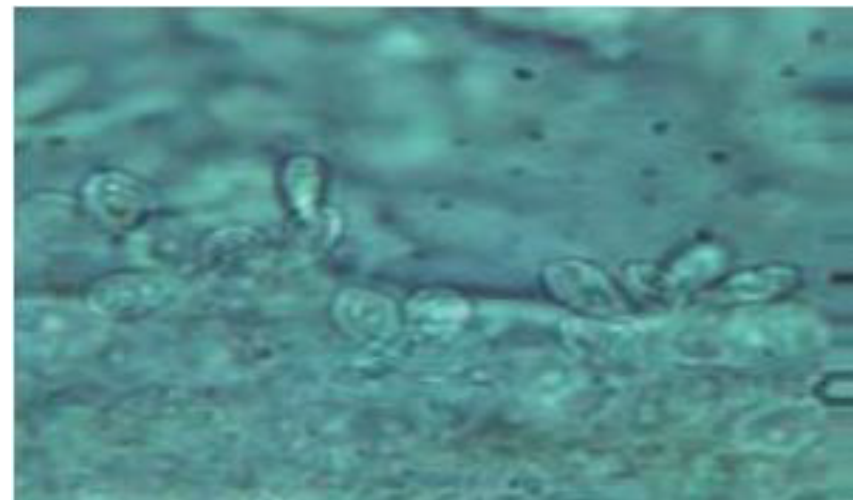

Figure 1b: Ichtyobodo sp.

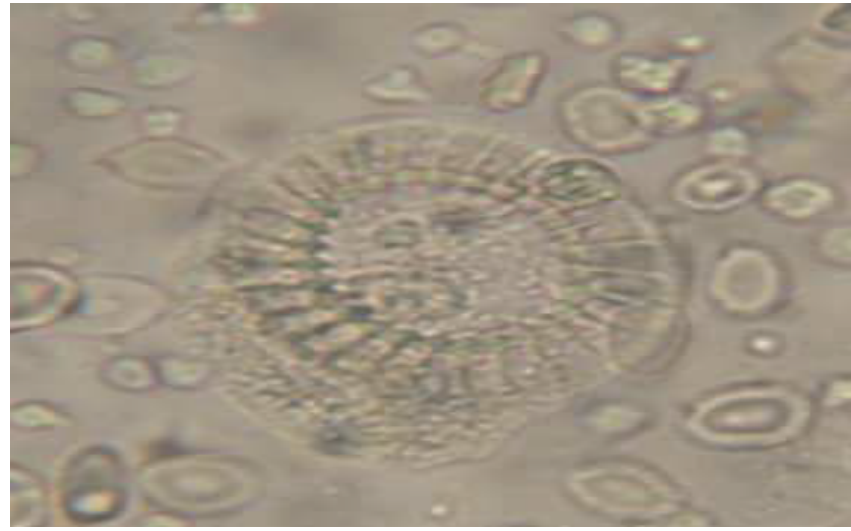

Figure 2a: Trichodina sp. found at the lining of the gills, HPO (400X).

(0.78), fish length and fish diameter (0.61) and fish weight and fish height (0.73).

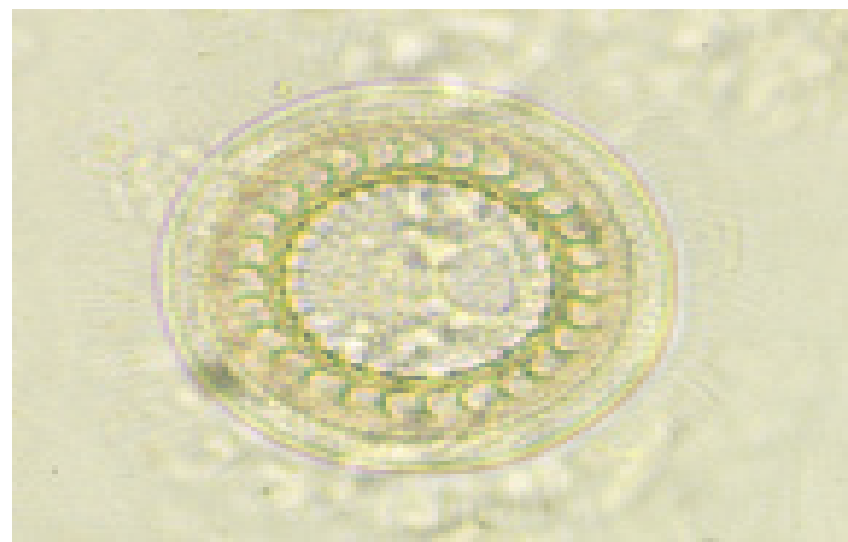

Figure 2b: Photo of Trichodina sp.

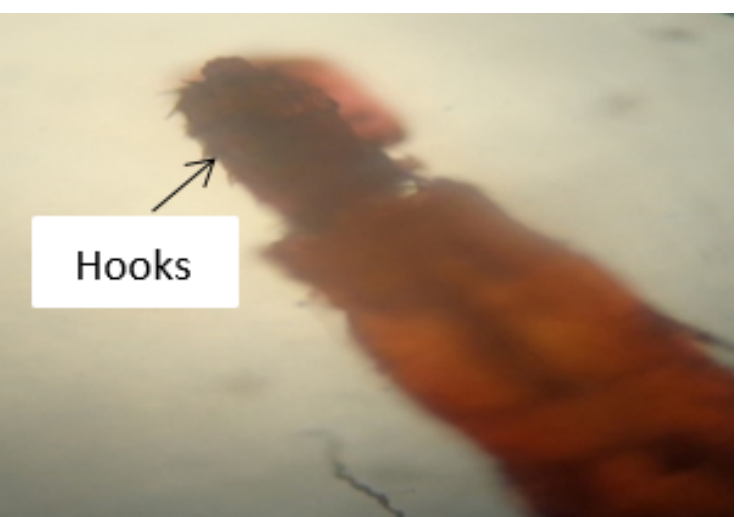

Figure 3a: Acanthocephalans spp. found in the intestine of C. Chano, HPO (400X).

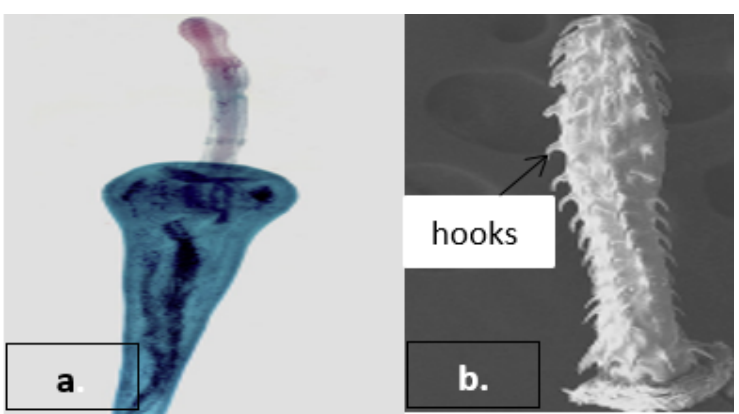

Figure $3 \mathbf{b}$ : Whole mount (a) and scanning electron micrograph of the proboscis (b) of Acanthocephalan spp. 
Citation: Echem RT, Barba HM, Guangyao Li, Peng F, Buenaventura NJC (2018) Endoparasites in Chanos chanos (Forsskal, 1775) from the wetlands of Zamboanga City, Western Mindanao, Philippines. J Aquac Res Development 9: 535. doi: 10.4172/2155-9546.1000536

Page 4 of 5

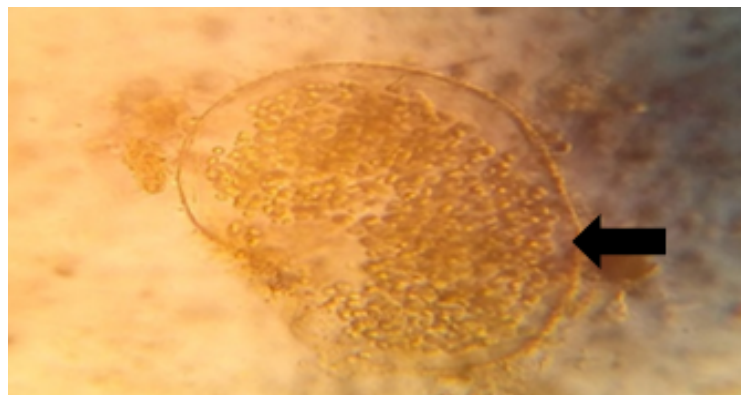

Figure 4a: Diphyllobothrium latum found at the intestine of $C$. Chanos.

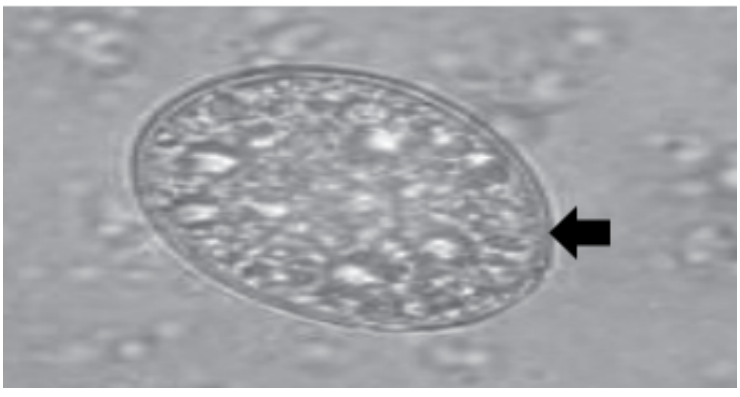

Figure 4b: Morphological appearance of $D$. latum.

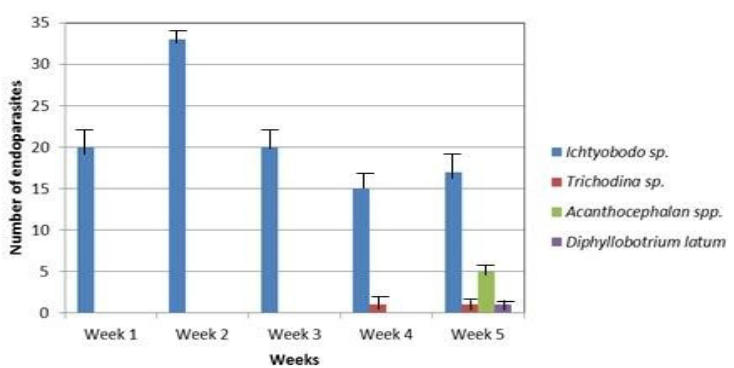

Figure 5: Number of endoparasites found in Chanos chanos.

\section{Discussion}

Velasquez [18] stated that the major parasitic group of milkfish in the Philippines include acanthocephalans, copepods, isopods, and heterophyid flukes. In this study, there were 4 different species of endoparasites identified from Chanos chanos through microscopic examination and direct inspection namely; Ichtyobodo sp., Trichodina sp., Acanthocephalan spp. and Diphyllobothrium latum.

Ichtyobodo sp. from the gills showed the highest number of individuals. Read [16] stated that this flagellate is an obligate parasite that depend its survival on its fish host. Ichtyobodosis is the disease caused by this protozoan parasite. Trichodina sp. and D. latum has the lowest number of individual. Many Trichodina species are pathogenic; this protozoan parasite glides rapidly over the gill and skin surfaces. Trichodina sp. can be present in low numbers and not cause disease [19]. Ichtyobodo sp. has the highest mean intensity and the most prevalent endoparasites found in C. chanos. According to Read [16], Ichtyobodo sp. may be free-swimming or attached in gill tissues which makes this protozoan endoparasite dominant and survives best compared to other endoparasites. External gross signs of the disease include excess mucus production and discoloration, removal of epithelium and gills may become swollen. Infected fish loss their appetite and sometimes die if there is severe infestation. Young fish are reported to be more susceptible to Ichtyobodo sp. than older fishes [20]. Ichtyobodo sp. causes large mortality rate not only in the wild but also in hatchery reared fish and even in-home aquariums [14].

D. latum has the lowest mean intensity and less prevalent. D. latum are intestinal worms that exploit freshwater copepods as their first intermediate host and freshwater fish as the second intermediate host [21]. D. latum is one of the longest intestinal tapeworms in humans and has numerous reservoir hosts. Aside from severe abdominal pain, the major symptoms of $D$. latum cases include minor gastrointestinal troubles such as abdominal troubles and abdominal distension. Trichodina $s p$. causes the disease known as Trichodinosis 16]. It is usually found on the gills but also can be found on the rest of the body, especially when the fish has become weakened. Infected fish often display lethargic behaviour, flashing and weight loss [18]. According to Berenji [22], Acanthocephalan spp. is an endoparasite found in the intestine of the fish host. A prominent characteristic of this parasite is its proboscis that is armed with recurved hooks, by which the worm attaches to the wall of the intestine of the definitive host. Acanthocephalan causes ulceration in the intestine of the fish [18].

Infection rate of the fish was high on the gills compared to the other parts. This is due to fact that the gills are in direct contact to the external water surrounding as a result of their respiratory activities [12]. The worms are only present in the intestine of older Bangus, this could be due to digestion process. Adult fishes consume a great variety of foods and exhibit a great variety of feeding styles [23].

There were no significant relations between fish length, weight and diameter and the number of endoparasites. This is consistent with the findings of Cauyan that linear correlations between total parasite count and fish total length showed negative relationships for all species. It also agrees with the findings of Amaechi [1] that there was no relationship between the endoparasites and size of the fish. Khalil [15] also stated that there was no relationship between fish length and parasitism, given that larger-sized fish were less affected by infection than the smallersized fishes. Relationship between the physical characteristics of $C$. chanos shows a high correlation. The longer the fish, the heavy it is and the bigger the diameter.

Difference in water quality between seawater and pond water such as reduced salinity, and methods involved in the management of ponds such as polyculture, may enhance mass infestation resulting in enormous losses [18]. According to Omeji et al. [24], the high infestation rate could be attributed to the sanitary condition of the ponds, the location of the ponds from residential areas, number and class of people visiting the ponds. The parasite prevalence and intensity depend on the parasite species, and its life cycle, host and its feeding habits. Other physical factors like water body where the fish inhabits, presence of intermediate host for the onward transmission of parasites and infection from another host. The hygienic condition of the water bodies are also very important in keeping aquatic environment free from introduction in any parasitic contamination from where fish are used for human consumption [23].

\section{Conclusion}

In this study, there were 4 endoparasites identified in Chanos chanos. Ichtyobodo sp. has the highest mean intensity and was the most prevalent endoparasites found in the gills of C. chanos. Diphyllobothrium latum has the lowest mean intensity and the least prevalent endoparasite. There was negative correlation between fish length, weight and body diameter and the number of endoparasites. However, there were strong correlations between fish length and fish weight, fish length and fish 
Citation: Echem RT, Barba HM, Guangyao Li, Peng F, Buenaventura NJC (2018) Endoparasites in Chanos chanos (Forsskal, 1775) from the wetlands of Zamboanga City, Western Mindanao, Philippines. J Aquac Res Development 9: 535. doi: 10.4172/2155-9546.1000536

Page 5 of 5

diameter and fish weight and fish diameter. These endoparasites can cause diseases to $C$. chanos.

Therefore, this study recommends that ectoparasites should be also studied, increase the number of samples, and include adult bangus. Freshwater and brackish water fishes like Chana striata, Anguilla marmorata and Caranx sp. will also be studied.

\section{References}

1. Amaechi C (2014) Prevalence, intensity and abundance of endoparasites in Oreochromis niloticus and Tilapia zilli (Pisces: Cichlidae) from Asa Dam, Ilorin, Nigeria. UNED Res J 7: 1-5.

2. Cruz-Lacierda $E$ (2012) Parasitic protozoans of farmed fish and crustaceans and parasitic helminths and annelids of farmed fish.

3. Lio-Po G (1984) Diseases of milkfish. In Juario JV, Ferraris RP, and Benitez LV (Eds). Advances in milkfish biology and culture: Proceedings of the second international milkfish aquaculture conference, 4-8 October 1983, Iloilo City, Philippines pp: 147-153.

4. Velasquez CC (1975) Status and needs of studies of fish parasites and diseases in the Philippines. pp: 73-94.

5. Velasquez CC (1979) Pests/parasites and diseases of Chanos chanos (Forsskal) in the Philippines. In proceedings of the technical consultation on available aquaculture technology in the Philippines. pp: 65-67.

6. Delmendo MN (1978) An overview of fish diseases and their control in aquaculture in the Pacific Region. paper prepared for the workshop on diseases of fish cultured for food in Southeast Asia, Cisarua, Bogor, Indonesia. p: 18.

7. Mercene EC (1978) Fish disease diagnosis centers in the Philippines: Pastand present research paper prepared for the workshop on diseases of fish cultured for food in Southeast Asia, Cisarua, Bogor, Indonesia.

8. Lio-Po GD, JP Pascual, Santos JG (1982) Country report on Philippine fish quarantine and fish diseases. Quarantine and Fish Diseases in Southeast Asia. pp: $35-46$

9. Cruz JD (2016) Milkfish or bangus aquaculture in the Philippines, Occidental Mindoro.

10. Yap W, Villaluz A, Soriano Ma G, Santos M (2007) Milkfish production and processing technologies in the Philippines.
11. Dioscoro M, Melana E, Mapalo A (2000) Mangrove management and development in the Philippines.

12. Bichi A, Ibrahim A (2009) A survey of intestinal parasites of Tilapia zillii (Gervias) in Tiga Lake, Kano, Northern Nigeria. Bayer j Pure Appl Sci 2: 1.

13. Cauyan G, Briones C, De Leon E, Gonong A, Pasumbal O, et al. (2013) Initial assessment of parasites load in Clarias batrachus, Glossobius gluris and Oreochromis niloticus in Lake Taal, Philippines. Philipp Sci Lett 6: 21-28.

14. Peek J (2012) Ectoparasites and intestinal endoparasites in channel catfish, Ictalurus punctatus in the Brackishwater River Missouri.

15. Khalil I, El-Shahawy S, Abdelkader S (2014) Studies on some fish parasites of public health importance in the southern area of Saudi Arabia. Rev Bras Parasitol Ve 23: 435-442.

16. Read P, Landos M, Rowland S, Misfud C (2007) Diagnosis, treatment and prevention of the diseases of the Australian freshwater fish Silver Perch (Bidyanus bidyanus).

17. Smith S, Schwarz M (2009) Dealing with Trichodina like species Virginia Tech. The Virginia Sea Grant College Program and Virginia Cooperative Extension.

18. Velasquez C (1984) Pests/Parasites and diseases of milkfish in the Philippines. pp: 155-159.

19. Durborow R (2003) Protozoan Parasites. Southern Regional Aquaculture Center.

20. Rogers W (1994) Ichtyobodosis. Alabama Agricultural Experiment Station Auburn University.

21. Arizono N, Yamda M, Nakamura-Hiyama F, Ohnishi K (2009) Diphyllobothriasis associated with eating raw Pacific Salmon. Emerg Infect Dis 15: 866-870.

22. Berenji F, Fata A, Hosseininejad Z (2007) A case of Moniliformis moniliformis (Acanthocephala) infection in Iran. Korean J Parasitol 45: 145-148.

23. Hussen A, Tefera M, Asrate S (2012) Gastrointestinal helminth parasites of Clarias gariepinus (catfish) in Lake Hawasa Ethiopa. Scien j ani sci 2: 1.

24. Omeji S, Solomon G, Uloko C (2013) Comparative study on the endoparasitic infestation in Clarias Gariepinus collected from earthen and concrete ponds in Makurdi, Bengue State, Nigeria. 